\title{
HOW MATURE TEACHING AND LEARNING CENTERS EVALUATE THEIR SERVICES
}

Susan R. Hines, Saint Mary's University of Minnesota

This study investigated faculty development program evaluation practices at thirty-three established, centralized, university-funded teaching and learning centers (TLCs). My prior statewide study (Hines, 2009) revealed that limitations of time, resources, and assessment knowledge resulted in superficial evaluation practices. Since the majority of respondents in the previous study were part-time faculty developers with limited funding and staff, I assumed that established, centralized TLCs would have the knowledge and resources to conduct a more rigorous evaluation. This study reveals that established centralized TLCs have significantly stronger practices for evaluating their services.

The field of faculty development emerged from a wave of academic accountability (Centra, 1976), and yet for years, minimal attention was given to program evaluation. According to early studies by Gaff (1975) and Centra (1976), faculty development program evaluation ranged from nonexistent to the occasional use of satisfaction surveys. Chism and Szabo's (1997) nationwide faculty development study noted a significant increase in the quantity of program evaluation but superficial quality as evidenced by widespread use of satisfaction surveys and routine gathering of self-reported changes in teaching.

In 2007 , I conducted a statewide study of the program evaluation practices of twenty faculty developers at public and private institutions (Hines, 2009). Paralleling Chism and Szabo's (1997) findings, results from this study indicated strong interest and limited rigor. Deficiencies in evaluation were most commonly attributed to a lack of time, resources, knowledge, and good evaluation models. Organizational factors may have contributed since the majority of the universities in the study took Minter's (2009) "point B" approach to faculty development. 
Minter (2009) devised a continuum of faculty development from point A to point $\mathrm{D}$. The point A approach (the "organized-centralized model" [p. 66]) is characterized by a centralized, well-organized, universityfunded unit led by a full-time director and staff responsible for developing and implementing faculty development activities for the university and its faculty and for evaluating the program outcomes. A point B program is led part time by a faculty member on release time and provides a variety of "semi-planned and ad hoc" (p. 66) events and activities with limited evaluation. Point $C$ is typified by a "totally or quasi-decentralized" (p. 66) approach in which deans or department heads plan events around their individual unit needs and budgets. Point $D$, the bottom of the continuum, is characterized by the absence of organized faculty development, leaving the faculty to self-direct their professional growth.

Of the twenty faculty development programs involved in my 2007 statewide study, seventeen were in the point B category and only three could be categorized as point A. Based on Minter's (2009) continuum, it was not surprising to find a preponderance of low-level evaluation practices. Therefore, the next logical step was to investigate the evaluation practices at point A teaching and learning centers (TLCs). TLCs were selected for this 2010 interview study using seven criteria: (1) a director (75 percent to full time) and staff dedicated exclusively to faculty development, (2) university funded, (3) separate and centralized location, (4) in existence for at least five years, (5) an articulated mission for the TLC, (6) a POD member, and (7) a U.S. university. These TLCs are referred to in this chapter as mature.

\section{Study Design}

Qualifying TLCs were identified through a cross-search between the list of more than nine hundred members of the Professional and Developmental Organization Network (POD) and member universities' websites. The website search and review resulted in fifty-six qualifying centers. The director of each TLC received an e-mail invitation to participate in the study, along with a request to confirm that the TLC met the seven criteria.

Thirty-three directors from qualifying TLCs agreed to telephone interviews. These interviews were chosen to allow in-depth inquiry, openended responses, and clarification of questions and terminology. The interviews were structured using a semiclosed, fixed-response, and openended questionnaire similar to those used in prior studies (Chism \& 
Szabo, 1997; Hines, 2009). Questions were designed to identify services offered; prevalence, type, and quality of evaluation practices; and reasons for gaps and limitations in their evaluation work. Participants received the questionnaire in advance of the interview and were asked to confirm or correct a postinterview transcript of their responses. All transcripts were then coded by the researcher and an outside coder, and interrater reliability was established through a series of independent coding and comparison sessions.

\section{Findings}

All participating TLCs could be characterized as point A on Minter's continuum. The participants were twenty-seven public and six private universities. Five had been in existence for five to nine years, seven for ten to fifteen years, thirteen for sixteen to twenty-five years, and eight for twenty-six or more years. All thirty-three were open year round. Four served fewer than one thousand faculty, thirteen served one thousand to two thousand, eleven served two thousand to four thousand, and five served more than four thousand faculty.

\section{Types of Services}

Services offered by the thirty-three TLCs were similar to those reported in Chism and Szabo's (1997) and my (Hines, 2009) studies. The majority provided seminars, workshops, brown bag sessions, conferences, and orientations, in addition to a variety of consultation services, online resources, and grant programs. Unlike the centers in the previous studies, over half of the TLCs surveyed sponsored faculty learning communities (FLCs). Approximately one-third designed customized programs such as faculty inquiry groups, academic fellowship programs, faculty writing programs, course revision programs, early and midcareer teaching programs, teaching enrichment series, interactive theater programs, and department-specific support programs.

\section{Staff Conducting Program Evaluation}

Most TLCs dispersed program evaluation duties among all staff members. The three TLCs with full-time staff assigned exclusively to evaluation indicated these were essential and fairly recent additions to their program. One director supported this recent appointment by saying, 
"If you're trying to figure out what's working, what's not working, and where to invest time and money, you need one." Another indicated that the need for evaluation staff was related to projects funded by government grants. All three reported significantly higher levels of program evaluation activity than the other TLCs in the study.

Individuals outside the TLC were also involved in program evaluation. Approximately 20 percent of TLCs hired outside consultants to perform periodic program reviews. Several tapped staff from their university's office of assessment. A small number recruited their advisory committees to review their physical and online teaching and learning resources.

\section{Prevalence of Evaluation}

All TLCs engaged in some routine evaluation, although disparities appeared in the types of services being evaluated (Table 20.1). A high percentage of TLCs evaluated, at least occasionally, user satisfaction and impact on teaching resulting from their events and activities, consultation services, and mentoring programs. Almost half of the TLCs offering grant programs, consultation services, or large resource events made

Table 20.I Percentage of TLCs Evaluating Satisfaction, Impact on Teaching, and Impact on Learning for Various Services

Percentage Evaluating Each Program Outcome

Number of

TLCs Offering Impact on Impact on

Type of Service the Service

Events and

Satisfaction

Teaching

Learning

activities

Consultation

26

$100 \%$

$94 \%$

$45 \%^{\mathrm{a}}$

services

Publications

and resources

Grant programs

33

81

81

47

Mentoring

24

52

21

0

programs

13

50

83

50

77

77

$2 \%$

Note. Percentages based on number of TLCs offering the service.

${ }^{2}$ Denotes high-impact activities only (large resource events such as writing improvement or instructional redesign) 


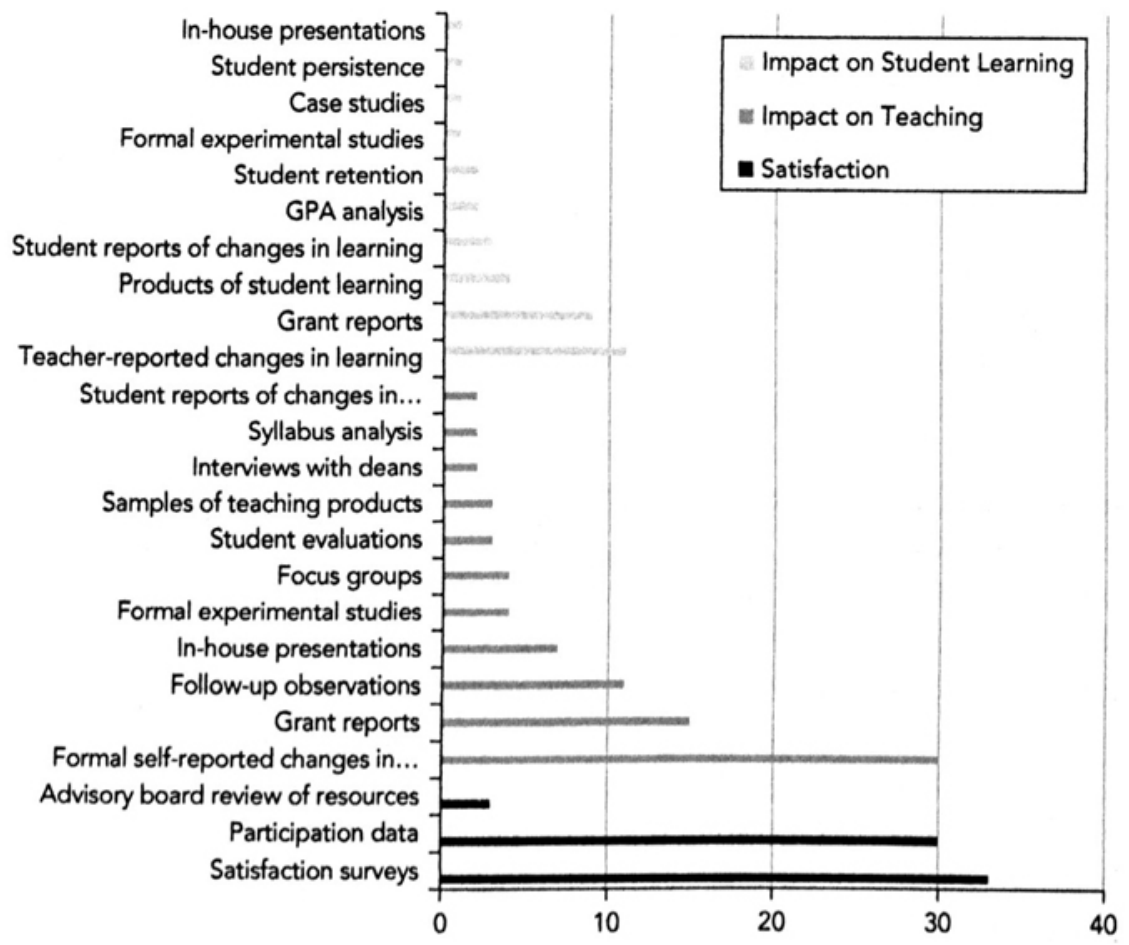

some effort to measure the impact these services had on student learning. There was little interest in gathering satisfaction or impact data relating to publications and resources.

\section{Evaluation Methods}

Evaluation methods most frequently consisted of satisfaction surveys, participation data, formal self-reported changes in teaching, grant reports, and formal teacher-reported changes in student learning, respectively (Figure 20.1). A variety of other methods were also implemented, although significantly less frequently.

\section{USAGE}

Participation and usage were commonly tracked. Attendance data included the department or school in which the participant taught. Usage data for online resources were frequently tracked using Google Analytics. 


\section{SATISFACTION}

Satisfaction was measured through the routine use of paper or electronic surveys administered after an event or service. Almost all participating TLCs reported the use of postevent meetings to debrief on satisfaction data and plan program adjustments. Three TLCs administered an annual survey, one administered a survey every four years, and two did an endof-term survey for consultations only. Anecdotal satisfaction data were rarely used. All respondents indicated a moderate to high level of satisfaction with their services. One TLC director was able to use an activity report listing annual services and events offered, combined with satisfaction, participation, and usage data, to persuade state legislators to avoid funding cuts that would have had a negative impact on the center.

\section{IMPACT OF SERVICES ON TEACHING}

Self-reports of changes in teaching were commonly gathered by embedding specific questions in satisfaction surveys. Typical questions were, "What will do you differently as a result of this program?" and, "What did you learn? Did you apply it?" Half of the twenty-four TLCs offering grant programs required recipients to report pedagogical changes that occurred as a result of the funded project. Many asked grant recipients to share their new instructional insights in a seminar, workshop, or poster session. Experimental data demonstrating instructional gains were collected if the design of the funded project produced such data. Evidence of pedagogical changes resulting from high-impact programs were gathered through focus groups, one-on-one interviews, and a review of instructorcreated products resulting from program participation.

Besides self-reports from follow-up surveys, teaching impacts from consultation services were often evaluated through follow-up classroom observations, if appropriate and permitted by the faculty member. Student evaluations were used with similar conditions. If a faculty member requested a small group instructional diagnosis, a follow-up was sometimes performed to gather student reports of changes in teaching.

The evaluation of mentoring programs relied heavily on self-reported changes in teaching solicited through e-mail inquiries and follow-up surveys. TLC directors also reported gathering feedback from mentors and mentees through focus groups, one-on-one interviews, pre-post examinations of syllabi, and pre-post reviews of student evaluations and in-class feedback. One TLC asked mentees to write "critical account" analyses. Two designed a formal experimental study using a control group (those not in the program) and an experimental group (those in the program) and compared gains, with one using tenure ratings as a measure. 
The impact of FLCs on teaching was most commonly measured through self-reported changes solicited through e-mail inquiries, focus groups, project reports, and presentations. One director conducted a retroactive faculty survey inquiring into the impact of FLCs on teaching careers over the past twenty years. A few used evidence-based measures, including teaching portfolios, classroom videos, and experimental studies, to measure gains in teaching.

\section{IMPACT OF SERVICES ON LEARNING}

Eleven of the fifteen respondents who measured impacts of events on learning solicited teacher-reported changes in student learning through surveys and interviews. FLCs were often evaluated in this manner as well. One respondent administered a five-year follow-up survey to 650 FLC participants inquiring into the perceived impact of FLC participation on student learning.

More robust evaluation efforts, reported by four respondents, targeted high-impact events where evidence demonstrating the return on the investment was required. Methods used to measure changes in learning varied by program. Programs designed to improve specific student skills (writing, for example) typically measured qualitative changes in products of student learning such as e-portfolios, writing samples, and capstone projects. Programs focused on changing instructional methods, such as large course redesigns, active learning initiatives, and cluster teaching projects, used pre-post quantitative measures of student course performance (for example, test scores, homework scores, drop-withdraw-fail rates) or overall academic success (for example, retention, persistence, grade point average). Instructional technology programs gathered reports of changes in learning through case studies, student self-reports, and student surveys. Combinations of these methods were included in reports from faculty who received instructional grants.

\section{Program Evaluation Purpose and Strategy}

Reasons for evaluation varied in frequency and type. All thirty-three TLCs studied evaluated program services for purposes of improvement: twenty-seven did so to document success, twenty-six wanted to see if their goals were met, ffteen reported that their administration required program evaluation, thirteen desired to do so, and one wanted to model evidence-based practices.

The production of an annual report summarizing program activity (participation, usage, and satisfaction) and linkage to program goals was the 
most common summative program evaluation practice, reported by twentyseven of the thirty-three participants. Seven of the thirty-three participants commissioned a periodic program review conducted by individuals outside their center. Four of thirty-three improved efficiency and focus, with staggered evaluation across individual program offerings from year to year.

The most systematic practices were reported by a director who developed a staggered and staged approach to program evaluation. A three-year evaluation plan, staggered program by program, was staged to measure three outcome levels: participation, implementation, and impact. The director first tracked participation data, noting, "It's not possible and there's no point to measure impact on student learning and teaching if participation is not present." After adequate participation became evident, evidence of implementation was gathered. Once the data indicated implementation, then impact on learning was measured. Implementation data were gathered through the diligent creation of "a one page case study (like a health record) with pre- and post-assessment data to look for improvement and holes in the process." Three weeks in July are set aside to analyze the data and write up the annual report, during which time all program activities and most services cease. The director readily admits this approach "is very hard work and very time-consuming" and emphasizes the crucial need for automation and customized databases to make this work, especially with limited staff. This unique approach captured valid evidence of significant impact and yearly progress that was published in the annual report.

\section{Reported Reasons for Gaps in Program Evaluation}

Evaluation of events and activities was performed to various extents at all responding TLCs. However, events seen as informal, infrequent, irregular, or lightly attended reportedly did not justify evaluation. Consultation services were not routinely evaluated due to the desire to maintain confidentiality and also the perceived lack of time and resources. A small number believed consultation evaluation to be too difficult or unnecessary, or the services too irregular, to justify assessing. Participants reporting a lack of evaluation for their occasional services, such as online and physical resources, grant programs, and mentoring programs, most commonly cited a lack of time and resources as the cause. Other respondents indicated that evaluation was too difficult to do, it was low on the priority list, there was no good process, or the informality of the services did not justify evaluation. 
The most common reason reported for gaps in evaluation regarding the impact of services on teaching was a lack of time and resources. Accompanying comments such as, "We want to, though, so we can show our dean for funding," and, "The scientist in me says it's a good approach, but between being a scientist or helpful, it's better to be helpful," highlight the conflict between desire and resource constraints. Others attributed the evaluation gap to the inherent difficulty and fear of causing survey fatigue.

The most common reason for not evaluating impacts on learning was a lack of time and resources. Several indicated that the presence of multiple confounding variables make the evaluation of impact on student learning very difficult. One respondent summed it up this way: "Being a psychologist with training in assessment, I know the level of effort it takes to do this well; anything less is a crapshoot or just a political tool."

At the conclusion of the interviews, many respondents remarked there was no reason to institute more rigorous program evaluation practices since administration already supports their work, suggesting that time, resources, and energy should go toward providing, rather than justifying, their services. An equal number of respondents reiterated the need for more staff and funding in order to develop more rigorous evaluation practices. For some, the absence of an institutional culture of assessment or leadership inconsistencies reduced their desire to improve program evaluation efforts. Others indicated that a lack of knowledge and absence of models for developing quality program evaluation plans greatly hindered their evaluation work. Disciplinary knowledge played a role and was reflected in comments such as, "We lack the knowledge in the staff. The director has a Ph.D. in social science, so there's a high standard for quality assessment with rigorous methods which we're [the rest of us are] unable to do" and "I have a Ph.D. in English, not stats. I would like to know how to do it."

Several other parting comments suggested strong interest and support for continued work in program evaluation:

"I'm interested in assessing for viability and sustainability but just don't know how."

"This conversation helped. We would do more evaluation if we had a better model on how to do it."

"We are well funded but would need a FIPSE [Fund for the Improvement of Postsecondary Education] grant to make a 
research report. We do need to move from self-reported changes to seeing it."

"Assessment is the future and accountability is critical, especially for federal and regional accreditation."

\section{Discussion}

Similar to the findings in Chism and Szabo's (1997) study and my own study (Hines, 2009), routine evaluation of services is prevalent among the mature TLCs studied. Unlike the previous studies, however, the mature TLCs that constituted this study group exhibited a stronger interest in extending measures beyond satisfaction and participation data to evaluation of program impact. The percentage of respondents making efforts to measure the impact of services on teaching was 20 percent in Chism and Szabo's (1997) study, 40 percent in Hines's (2009) study, and 97 percent in this study. The percentage of respondents attempting to measure the impact of particular services on learning was insignificant in Chism and Szabo's (1997) study, 20 percent in Hines's (2009) study, and 45 percent in this study. This increase in impact measures of teaching and learning is encouraging, but it is tempered by the majority reporting only superficial measures of selfreported changes. However, recognition is due to the increased prevalence of grant programs requiring evidence of changes in teaching and learning and of the implementation of periodic program reviews, both of which were rare to nonexistent in the previous two studies. In addition, this study revealed some noteworthy efforts by a select few who devoted extensive effort to gathering causal evidence of high-impact events on student learning through pre-post measures and experimental studies using multiple measures. In addition, reports of using anecdotal data were offset by substantial reports of systematic formal evaluation methods with a high reliance on technology in the form of online surveys, Google Analytics, and databases.

As has been reported for decades in the literature, many of the respondents reported gaps and superficiality in evaluation practices, with most blaming the lack of time and resources. Some individuals formally trained in assessment could not justify the time and effort to demonstrate their worth when administration already believed in them. Others felt they lacked useful models or staff with assessment knowledge.

Unlike reports from previous studies, many TLCs report efforts to overcome the obstacles of time and resources by implementing changes 
to their evaluation practices and staffing. The TLCs most active in evaluation have systemized their evaluation process in these ways:

- Automating attendance and online surveys

- Evaluating their programs on a staggered annual basis

- Evaluating outcomes in a staged manner

- Using random sample data collection methods

- Reserving rigorous evaluation for high-impact programs

- Leveraging support from deans or department chairs

- Creating a strong culture of assessment within the center

- Hiring full-time evaluation staff trained in program evaluation

\section{Recommendations}

Considering the findings from this and earlier studies, it appears that the most feasible and useful evaluation practices should be designed within a culture of assessment. This work can be summarized in what could be termed the four S's of program evaluation: staffing, systemization, staggered evaluation of programs, and staged outcome evaluation.

\section{Staffing}

Build staffing and institutional collaboration to support program evaluation efforts. Distribute data gathering among staff or, ideally, assign it to a full-time staff specialist hired specifically for program evaluation. In addition, collaborate with the university's office of assessment to design evaluation plans, provide readily available institutional data, and combine survey efforts.

\section{Systemization}

Create a comprehensive plan to systematically gather data for evaluating the program. Determine the goal of the program, the outcomes to be measured, the methodology and timing for data collection, and the schedule for analyzing, reviewing, and implementing the findings. Customize the plan to fit the resource limitations. Where possible, use technology such as online survey software, content management servers (such as SharePoint), database software, and student response systems (clickers) to automate the collection and analysis of data. Simplify survey distribution by standardizing surveys, using preexisting institutional data, 
and combining survey efforts with other institutional assessment efforts. Embed evaluation in program planning as part of standard practice along with annual reports or fact sheets to track and report program trends and success.

\section{Staggered Evaluation of Programs}

Evaluation of the entire TLC does not need to occur at one time. Stagger the evaluation of individualized programs or services on an annual basis. Create a three- to five-year plan outlining the staggered evaluation of each component of the TLC. For example, in year 1, evaluate consultation services; in year 2, evaluate the teaching certificate program; and in year 3 , evaluate the mentoring program.

\section{Staged Outcome Evaluation}

Take a staged approach to the evaluation of outcomes of various programs. For example, for any given program, track participation only until a significant number is achieved. Then gather data to determine if participants are implementing the new skills. Finally, measure the impact on student learning once significant implementation is seen. Another approach could be to tailor evaluation to selected outcome measures most appropriate to the intended impact of the individual programs or services. For example, satisfaction data may suffice for ad hoc workshops, data about impact on teaching may be needed for mentoring programs, and data concerning impact on student learning may be important and feasible for grant-funded teaching projects. In other words, collect data that will add value to the center's work.

\section{Conclusion}

Directors of mature TLCs are interested in program evaluation and need feasible and useful evaluation models. The findings of this nationwide study suggest that staffing, systemization, staggered evaluation, and staged outcome measures are a useful framework for the design of evaluation methods to demonstrate the worth and inform the continuous improvement of faculty development services. Continued efforts must be put forth to share best practices in program evaluation through scholarly research, consortiums, publications, conferences, and presentations. Continued research is needed to find ways to measure the impact of faculty development on teaching and learning. Perhaps this director's closing 
remark best captures the need for continued research: "We're still asking, 'Does faculty development make a difference?' I don't think anyone has a good answer to that yet."

\section{REFERENCES}

Centra, J. A. (1976). Faculty development practices in U.S. colleges and universities. Princeton, NJ: Educational Testing Service.

Chism, N.V.N., \& Szabo, B. L. (1997). How faculty development programs evaluate their services. Journal of Staff, Program, and Organizational Development, 15(2), 55-62.

Gaff, J. G. (1975). Toward faculty renewal. San Francisco, CA: Jossey-Bass. Hines, S. R. (2009). Investigating faculty development program assessment practices: What's being done and how can it be improved? Journal of Faculty Development, 23(3), 5-19.

Minter, R. L. (2009). The paradox of faculty development. Contemporary Issues in Education Research, 2(4), 65-70. 


\title{
FACULTY DEVELOPMENT AS A HAZARDOUS OCCUPATION
}

\author{
Linda B. Nilson, Clemson University \\ Edward B. Nubfer, California State University, Channel Islands \\ Bonnie B. Mullinix, TLT Group and Greenville Technical College
}

"Hazardous" describes events and conditions that produce an undesired, involuntary, career-changing disruption of a developer's professional practice. While faculty development is an immensely valuable asset to an institution that knows how to make use of it, the unique nature of faculty development centers within varied academic institutions brings occupational hazards to those who direct or work in such centers. Our study synthesizes and identifies patterns among over thirty cases furnished by developers, primarily center directors, who experienced career disruptions. We conclude by offering evidence-based counsel on how to recognize the hazards and mitigate damage.

The twenty-first century began with an optimistic observation about our profession: "Never before in the history of education has greater importance been attached to the professional development of educators" (Guskey, 2000). More recently, Brownwell and Swayner (2010) advised institutions to "invest in faculty development" because instructional practices that promote student success require support and expertise to implement properly. Research increasingly shows that development helps faculty acquire the skills that promote and strengthen student learning (Nuhfer, Blodgett, Fleisher, \& Griffin, 2010). Indeed, those who persist in this occupation often acknowledge that their motivation is fueled by its far-reaching power for good; helping a faculty member succeed helps every student whom that faculty member touches.

This same decade also saw the emergence of literature alerting faculty developers to their need to justify, defend, and secure their center's existence. 
Publications and conference sessions suggested the importance of conducting program evaluations to document the positive impact of teaching and learning units, particularly for administrators and external audiences (Bothell \& Henderson, 2002, 2003; Burkin, Chism, Frerichs, \& Wehlburg, 2003; Cafarelli \& Jones, 2002; Faculty and TA Development, 2004; Way, Carlson, \& Piliero, 2002). Terms such as "return on investment" (Bothell \& Henderson, 2002, 2003), "stakeholders," and "utilizationfocused evaluation" (Cafarelli \& Jones, 2002; Patton, 1998) entered the lexicon of center directors. Forums on the survival of faculty development (FD) centers (for example, Nilson, 2003; Nuhfer et al., 2003) became well-attended events at developer conferences. Ewing and Sorcinelli's (n.d.) justification for FD, "The Value of a Teaching Center," appeared in 2004 as a permanent fixture on the POD Network website. Concern was raised more broadly as well. Gosling, Chism, and Sorcinelli (2008) synthesized the results of their surveys, conducted in five separate studies, of over one thousand respondents from eighteen countries (primarily the United States, the United Kingdom, Canada, Australia, and South Africa) on the current and future challenges facing FD. They found that "organizational volatility" creates a constant disruption.

A catalyst for this second body of literature was the shock generated by the unexpected closure of one of the first American FD centers at the University of Nebraska, Lincoln (Bartlett, 2002). More center closures followed (Glenn, 2009), even as new centers and developer positions opened. The trend confirmed the risks of being a faculty developer. This organizational volatility appeared to come not from any organized national movement but from local reorganizations too numerous to ignore. It was difficult to reconcile that while assessing student achievement was becoming a national priority, the profession that directly supports instructional improvement, student success, and faculty effectiveness was being locally undercut.

Developers quickly recognized this trend in open exchanges at conferences and the POD Network listserv. Critical changes and closures were sometimes common knowledge across the profession before they were announced at the home campus. Developers who survived such career disruptions and managed to stay in the career they love understand both the hazards and how to survive them. We are three such developerssuccessful and survivors. This study synthesizes the case experiences of thirty other similar survivors. We thank them for their knowledge and their courage in participating in this study. 


\section{Methodology and Approach}

Because career disruptions are complex and emotionally evocative, our study of the subject called for qualitative approaches and data collection strategies that guaranteed anonymity. We communicated through personal e-mail and telephone accounts, avoiding institutional accounts that are routinely archived and may be treated as public record.

Our study began with case interviews and narratives aimed at gathering thick data that could be mined for emergent themes and grounded in context-rich descriptions (Strauss \& Corbin, 1998). We openly introduced our study and its purpose through an announcement on the POD listserv inviting colleagues to confidentially contact us to share their personal stories of center closures, position eliminations, or forced resignations. We used the initial communications to develop potentially generative prompts for a thirty-item case interview outline. We selectively followed up to obtain more detail, encouraging participants to address items that resonated with their experience. Responses varied widely, from a sentence or two per item, to lengthy narratives, to detailed answers to all thirty items. Grounded theory informed both the study's design and analysis strategy that relied on capturing emergent themes and allowing their growth and ongoing validation (Strauss \& Corbin, 1998). Because we as researchers were also participants, the study benefited from the increased emic validity characteristic of participatory research (Freire, 1972).

This data-gathering strategy yielded thirty-three cases of center closures, position eliminations, and forced resignations from center positions. Our participants were active or recently active POD members, and thus our study omits any who left the profession. Our database consists of center directors except for one associate director, one senior consultant, and one coordinator. The vast majority of these incidents took place within the past eleven years, and three cases were from outside the United States.

Our sample of about three hazards a year over the past decade should not be mistaken as representing small impact. FD is a tiny profession of about eighteen hundred POD members and 1,267 teaching and learning centers at 933 different institutions (Kuhlenschmidt, 2011; S. Kuhlenschmidt, personal communication, January 30,2011$)$. To draw scalable comparisons from numbers of faculty in some common disciplines (U.S. Department of Labor, 2011), the closure of three FD centers a year is roughly equivalent to the closure of about 150 fine arts programs, 
120 English departments, 90 math programs, or 40 history departments.

The thirty-three cases broke down into these subcategories:

- Twenty-three cases of closed centers, which happened twice to one person

- One case of a center that was gutted but technically not closed

- Five cases of eliminated positions, two of which happened to one person

- Four cases of directors terminated without cause

We classified as "closed" two cases of "ghost centers." These units had closed and development no longer existed, but the institutions retained the defunct centers' website.

Our study spans a wide range of Carnegie classifications. Table 21.1 shows the degree to which our U.S. sample of thirty disrupted centers represents the actual distribution of higher education institutions across Carnegie categories and the percentage of institutions in each category with a teaching and learning center, as identified by Kuhlenschmidt (2011). Our sample considerably overrepresents research universities and underrepresents associate of arts colleges. The three cases from outside of the United States were from research-oriented institutions enrolling between fifteen thousand and forty thousand undergraduate and graduate students.

The second phase of the study involved a well-attended roundtable session (Nuhfer, Mullinix, \& Nilson, 2009), hereafter referred to as the roundtable. Held in a private meeting room, this session provided an opportunity to acquire data in an interactive setting. Nineteen colleagues attended; fourteen disclosed their surviving at least one career disruption. Building on preliminary findings, we developed two data collection exercises to solicit additional data: a line exercise and a themed response exercise. In the line exercise, all participants stood shoulder to shoulder in a straight line. They were instructed to take one step forward from the line if the statement that the author-facilitators read described their experience, returning to the baseline following each statement. Counts were taken of each line advancement by participants. In the themed response exercise, nine reasons for career derailments drawn from the cases and our own experiences, plus "other" and "I have no idea," were themes heading eleven blank posters on the walls around the room. Participants used sticky notes to provide details on their cases and affixed these to the posters most closely related to their experiences. 
Table 2 r. I Comparison of Our U.S. Study Sample with the National Percentages of Institutions in Carnegie Categories and National Percentage of Institutions in Each Category with Teaching and Learning Centers

\begin{tabular}{|c|c|c|c|c|}
\hline Carnegie Categorya & $\begin{array}{c}\text { Percentage of } \\
\text { Institutions } \\
\text { in Carnegie } \\
\text { Category }\end{array}$ & $\begin{array}{c}\text { Percentage of } \\
\text { Institution in } \\
\text { Each Category } \\
\text { with Centers }\end{array}$ & $\begin{array}{c}\text { Percentage } \\
\text { of Category } \\
\text { Represented } \\
\text { by } \\
\text { Disruptions } \\
\text { in Our Study }\end{array}$ & $\begin{array}{c}\text { Number of } \\
\text { Disruptions } \\
\text { by Category } \\
\text { Reported in } \\
\text { Our Study }\end{array}$ \\
\hline $\begin{array}{l}\text { Doctoral/Research } \\
\text { Universities, } \\
\text { Extensive }\end{array}$ & & & & 7 \\
\hline $\begin{array}{l}\text { Doctoral/Research } \\
\text { Universities, } \\
\text { Intensive }\end{array}$ & & & & 1 \\
\hline $\begin{array}{l}\text { Research } \\
\text { Universities, Very } \\
\text { High Research } \\
\text { Activity }\end{array}$ & $6.5 \%$ & $22 \%$ & $53 \%$ & 3 \\
\hline $\begin{array}{l}\text { Research } \\
\text { Universities, High } \\
\text { Research Activity }\end{array}$ & & & & 5 \\
\hline $\begin{array}{l}\text { Master's Colleges } \\
\text { and Universities I }\end{array}$ & $15.2 \%$ & $28.2 \%$ & $23.3 \%$ & 7 \\
\hline $\begin{array}{l}\text { Baccalaureate } \\
\text { Colleges, Liberal } \\
\text { Arts/Arts and } \\
\text { Sciences }\end{array}$ & $17.6 \%$ & $11.8 \%$ & $10 \%$ & 2 \\
\hline $\begin{array}{l}\text { Baccalaureate } \\
\text { Colleges, Diverse } \\
\text { Fields }\end{array}$ & & & & 1 \\
\hline $\begin{array}{l}\text { Special Focus } \\
\text { Institutions }\end{array}$ & $19.2 \%$ & $4.6 \%$ & $6.6 \%$ & 2 \\
\hline $\begin{array}{l}\text { Associate of Art } \\
\text { Colleges }\end{array}$ & $41.6 \%$ & $33.5 \%$ & $6.6 \%$ & 2 \\
\hline
\end{tabular}

Note. All nonsample percentages are from Kuhlenschmidt (2011). "Italics in this column show the general category. 


\section{Findings from the POD Listserv Call on Career Derailments}

The narratives we received revealed both the vulnerable institutional status of our profession and the personal costs to developers who suffer a disruption. They also provided contextual data that informed the exercises we led at the POD conference roundtable.

One survivor captured the experiences of several others, attributing the demise of his or her center to budget cuts: "When funding is tight, FD is the first to be cut or changed in some fashion to meet other institutional needs."

Another attested that a glowing campus reputation and data-rich program evaluations made no difference to his or her center's survival:

Last fall the provost reviewed all the units of the [division] and came back with the finding that [the center] was the only unit of the [division] to have a uniformly positive reputation on campus. We never had acknowledgment of that finding from the new [administrator], or other feedback except for his occasional observation that [center] consulting is very labor-intensive and (by implication) very expensive. Our years of impact assessment, self-studies, regular client feedback, and annual reports don't seem to have been enough to alter this perception.

A two-time survivor (one of two) identified the disinterest of both of his or her administrations in FD:

Neither administrators were interested in the work [of the center] because their mandate, personal or institutional, did not include the continuance of professional faculty development services. In both cases, I was told, in the end, that I was doing an "excellent job" and was "obviously well-known in my profession" and therefore could easily find another position.

The duplicity between the praise noted for doing "excellent" work and the immediate humiliation of the developer was revealed later in the narrative:

In case B, I was literally escorted back to my desk by a campus security officer and told to pack up in an hour or two. I had my entire professional library there, so it took nearly all day to pack things up. My email access was cut off within minutes of my return to my office after the meeting. My laptop was confiscated and a copy of my hard drive made.

As we expected, survivors varied widely in how they reacted to losing their position. Fortunately, this response represented that of many: "And 
I am not a loser at all, just a person caught in a web I didn't make. I will survive this." It shows a rejection of victimhood and a refusal to allow mistreatment to strip self-worth.

But another case belied a sad, entangled combination of pragmatic pessimism, self-blame, and disappointment:

I spent XX years there, and I'm afraid I leave with much less optimism, and even a touch of bitterness. I felt through all my years in faculty development that I was there to help and serve the faculty, and I know I did good work, and helped people. But somehow I never convinced administrators that this was all worthwhile-a fundamental failure of mine, I believe. My experience in faculty development convinces me that it is indeed hazardous, and vulnerable to the winds of regime change. After all, administrators score bullet points on their résumés by starting new initiatives, not continuing existing offices, even successful ones. Would I do it over again? Faculty development was a huge part of my life for many years, but I look back on it as essentially a failure. I don't think I would want to do this again.

In contrast was this survivor's unadorned realism about how practitioners should regard their work and define their jobs:

If [new] faculty developers go into the workplace believing that their job is to apply their passion and contribute to faculty and student learning ... that is a pretty "novice" stance ... and one that is going to translate to dismissal. As we develop professionally, we begin to see that part of our job description is to continually watch the landscape (and the rats) to make sure that faculty and student learning remain part of the mix in the goals of the institution.

\section{Findings from the POD Conference Roundtable on Career Hazards}

As did respondents to the listserv call, roundtable participants described center closures, position eliminations, and forced resignations. From the line exercise, we tallied fourteen survivors' perceptions of the institutional conditions and professional ramifications of the derailments and their personal feelings about the incident (Table 21.2).

As shown in part $A$ of Table 21.2, half of the survivors had experienced more than one career disruption, and eight of them had no tenure protection. The effects of these hazards were distributed across job loss, undesired reassignment, intolerable changes, and harassment. FD services disappeared in nine cases (64 percent), most under the guise of "decentralization." 


\section{Table 21.2 Response Tally of Line Exercises Conducted During the} 2009 POD Conference Roundtable

Number Percentage

\section{A. The nature of the hazard}

1. You experienced as a developer a career disruption you would term a hazard that resulted from an

experience beyond your control.

1.1. Take a second step forward if you experienced more than one such hazard.

2. You actually lost your livelihood for a time as result of such a hazard.

3. You did not lose your livelihood but were reassigned into another position not of your choosing.

4. You were not reassigned but removed yourself from a situation that was too distressing to tolerate.

5. The hazard involved harassment such as others trying to damage your professional reputation or credibility.

6. The development services to faculty went away after the event.

6.1. Take a second step forward if the institution claimed the services would not be curtailed but simply

"decentralized."

7. You sought legal counsel.

8. Your institution reneged or tried to renege on a contract.

9. Your institution reneged or tried to renege on promises made when you accepted the position of developer.

10. You had no tenure retreat rights protection from the hazard.

B. Personal feelings

1. You felt devastated. $\quad 8$

2. Your confidence in your own competence was shaken. 3

3. You felt abandoned or betrayed by your supervisor. $\quad 9$

4. You felt abandoned by formerly supportive colleagues. 117

5. Your quality of life felt significantly diminished. 9

6. You remained upset or angry a year or more after the event.

7. You sought professional help as a result of the event. 
Six of the institutions reneged on earlier promises, and two violated contracts, prompting the survivors to seek legal counsel. In these latter cases, administrators attempted to access salary resources through intimidation, threats, reassignment, and pressuring individuals to sign contracts at lower salary levels. In the end, their lawyers successfully argued that contracts are binding; the institutions had to pay the contracts in full.

Part B of Table 21.2 details the human cost of the disruptions. Every type of injury listed was chosen by one or more survivors, validating these thematic categories while underscoring the complexity of the experiences and the strength of the emotions they evoked. The most commonly experienced emotions were feeling abandoned or betrayed by a supervisor, a significantly diminished quality of life, remaining upset a year or more after the event, and general "devastation." Yet all were true survivors, working again in a new job and actively participating at their national meeting.

The themed response exercise tallied developers' perceptions of the reasons for the disruptions they experienced (Table 21.3). With nine responses, the most common reason was "lack of recognition and understanding of the FD (faculty development) profession and its functions," followed by "budget cuts" with seven responses. Although we would expect budget issues to rank high, the apparent inability of upper-level administrators to make use of our profession reveals a need to educate them in how to use FD to further the success of their institutions. "Lack of administrative support for FD unit" attracted four comments, one of which was particularly revealing: "Looking back, I think administrators thought of FD as a nice ornament to hang out during the accreditation visit. FD got a good rating from the accreditation team, and we were the only unit in academic affairs that did. This made some above us uneasy."

Several participants expressed lingering bewilderment. As one put it, “Explicitly 'No real reason given.' Implicitly many possible unstated reasons. ... And remember, we are all serving at the pleasure of the president." Another case of "giving no reason" centered on a new president who replaced many established administrators with appointees and targeted professional reputations in the process:

"We can't tell you; it's a confidential personnel decision." That's what they would tell anyone they wanted to harm. Then the "confidential decision" would appear in the front page of the paper or be pumped out to the campus and the world via spam email. Sometimes the announcement appeared with the victim's campus ID photo but never with reasons or cause-just enough of a spin to make it appear the victim had done something wrong. 
Table 21.3 Response Tally of Themed Posters Exercise Conducted During the 2009 POD Conference Roundtable

Reasons for Career Derailment

1. Budget cuts (not reallocation)

2. Budget seizures/reallocations by new administrators (not cuts)

3. Conflicts as result of being an advocate for faculty/ teaching

4. Another person wanted/awarded your job or a patronage appointment

5. Lack of administrative support for FD unit

6. Deans/chairs redefine FD as travel to meetings, etc.

to get at center's funds

7. Lack of recognition and understanding of the FD profession and its functions

8. Turf perceptions-others believe they should be in charge of FD

9. Personal or stylistic conflicts between developers and others

10. Other

Personal vendettas

Supervisor of supervisor overrides supervisor

"Psychopathic" supervisor

11. "I have no idea."
Number Percentage

50

5

36

3

21

7

29

1

7

9

64

5

36

$5 \quad 36$

$8 \quad 57$

$4 \quad 29$

$1 \quad 7$

17

$5 \quad 36$

\section{Lessons Learned: Hazards}

The rich qualitative data collected across the interviews, cases, and roundtable exercises provided insights to hazards that might serve as warning signs for threatened centers.

\section{Lip-Service and Ghost Centers}

Universities have evolved to regard certain components as indispensable-for instance, human resources, the general counsel, admissions, accounting, financial aid, development, and the research office. FD does not fall among these select units. Because it supports faculty and successful teaching and learning, it is only as stable as an institution's commitment to faculty and student success. While regional accrediting agencies 
may require $F D$, institutions can meet this requirement by maintaining centers through the accreditation review process and dismantling them soon afterward. During the hiatus, a center's website may remain for appearances' sake or the title "faculty development" may be given to a person or unit that does no substantial development. Such situations constitute the ghost centers we noted earlier. A few of our survivors reported witnessing and falling victim to this kind of bait and switch. Before accepting employment at an institution, it is wise to determine whether the administration ever maintained a ghost center.

\section{Institutional Conflict and Culture Clash}

Several survivors described internal conflicts between the institution's stated and enacted teaching mission or between the faculty and the administration, or both, as terminal to FD. Centers seem to fare better in a culture that is unequivocally committed to teaching and student success and is not compromised by distrust and discord between faculty and administrators. While a center can strongly influence an institution's culture, it cannot create or change its enacted mission.

\section{A Changing of the Guard}

In general, higher-level administrators change campuses more frequently than do faculty, and they bring their perceptions of FD with them when they move. In some places, the faculty developer is a full-time professional; in others, development is a part-time duty for a faculty member; and on many campuses, the faculty developer is a rotating position held by a professor for two or three years. Administrators who serve in institutions that invest in a full-time professional developer see developers differently from administrators who view $\mathrm{FD}$ as service. When the latter move to the former kind of campus, they will not understand the value of a full-time developer and a permanent center and will probably have other priorities. Survival after a changing of the guard may depend on expanding a center's mission and services to encompass what the new campus leaders value. Therefore, directors must be nimble enough to broaden their development programming from teaching alone to scholarly research and writing, grantsmanship, publication, student retention, leadership, assessment-whatever the new priorities may be. But the new administrators must be willing to meet with center directors regularly to learn how the developer can support their new vision. Among our survivors, the lack of willingness to meet was a sure sign of disruption 
to come. No matter how compelling the evidence of the center's benefits in its program evaluations, directors who lacked access to administrators were soon terminated, usually along with their entire center, without explanation.

\section{Reorganization from the Top}

A considerable number of our survivors fell victim to reorganization plans imposed from the top, with little or no faculty input or buy-in. These plans orchestrated a redistribution of resources that involved the elimination of units and positions, incompatible mergers, and unfavorable reassignments. Some were allegedly done to save money in the face of budget cuts. In our study, the most common reorganization involved FD's being “demoted" from a free-standing unit to a program within instructional technology (IT). In most such cases, the larger and wealthier IT focus drove the unit's mission, eclipsing teaching with technology.

\section{Resentment and Destructive Gossip}

A few survivors experienced some faculty resentment about their newly established center from faculty, often in a school of education or psychology department, who believed that they were more qualified to do development than the director was. They might have even been unsuccessful internal candidates for the position. One survivor raised this hazard as probably costing his or her job, and this person unwisely responded in kind to the gossip that the malcontents were spreading. Survivors who rose above such behavior by neither opposing their critics nor gossiping about them fared better. The restrained response gradually disarmed the critics and won their trust. For instance, one director read their pertinent literature, invited them to participate on a center project, and expressed respect for their contributions. Reaching out to detractors in this way can turn those who once felt disenfranchised into strong supporters as the developer's success is now theirs to share.

\section{Exclusion from Relevant Decision-Making Forums}

Many of the directors in this study noted that shortly before their career disruption, they were not being asked for input in decisions that were relevant to teaching and learning or to their centers. Some had never been invited to the table; others had been in the past. The astute directors saw 
such exclusion as a signal that the administration had little interest in faculty development and correctly read it as a sign of bad things to come. Being left out of regular communication and decision making diminishes any professional's ability to be effective.

\section{Lessons Learned: Hazard Insurance}

Our study suggests strategies for managing a successful FD career. Like insurance, these strategies cannot prevent hazards, but they can surely mitigate damage.

\section{Tenured Faculty Status}

While faculty status lends credibility to developers (Mullinix, 2008) and tenure facilitates survival within the academy, tenured faculty status cannot prevent disruptions in a faculty developer's career, but it can provide insurance against some effects. Ten of the thirty-three survivors we interviewed and six of the fourteen who participated in the poster exercises held retreat rights in an academic department. Remaining in the academy allowed them to retain academic credibility and provided precious income and stability while they searched for another development position. Several chose to take an FD position elsewhere, demonstrating that the desire to remain in this field can trump the security of tenure. Tenure also makes a center less attractive to an administrator who hopes to seize its resources because the salary and employer-paid benefits of any tenured personnel are unavailable for reallocation. Still, the salaries and employer-paid benefits of untenured personnel and the operating budget are vulnerable.

\section{Center Visibility, Credibility, and Friends in High Places}

In the words of one survivor, "Keeping a higher institutional profile is, in general, the best assurance of longevity. . . . If no one makes a fuss when they hear your program is threatened, it's an easy street for the administrator doing the cutting." One case described a "nearclosure"-actually a one-month closure that was reversed when several deans and the faculty senate learned of the administrator's action and pressured her to reverse the decision. In essence, important parties made a fuss because the center was a well-established, high-profile, widely used fixture on the campus, and key people understood the value of its services. This happy ending, however, represents the exception, not the rule. Survivors with successful centers, professional distinction, and no 
shortage of faculty friends and allies still fell victim to administrative manipulations.

\section{Supportive Professional Networks}

Some survivors recounted that professional networks beyond their campus were sources of career opportunities and the strong recommendations they needed to land a new position. Network members, especially experienced survivors, provided emotional support and useful perspectives. While cultivating national, regional, and local networks of close colleagues and professional friends involves time and work-socializing at conferences, providing service to professional organizations, and participating visiblyit can be one of the best investments against career hazards.

\section{Productive Scholarship}

Tenured faculty in disciplines who let their scholarship atrophy are not mobile and cannot pursue more attractive opportunities. The same holds true for the profession of FD. As our study shows, career derailments can happen to the best of developers, no matter what their accomplishments in and outside their institution. However, the survivors who were able to recover in the shortest time had an impressive record of scholarly accomplishments, including publications, conference sessions, and invited presentations.

\section{Conclusion}

FD carries unique occupational hazards. Where developers address the hazards, disruptive and painful though they may be, they can and do survive. In spite of its hazards, the career is worth the risks. Why else would so many developers persist and respond to disruptions with such inspiring resilience?

\section{REFERENCES}

Bartlett, T. (2002, March 22). The unkindest cut: The struggle to save a teaching and learning center. Chronicle of Higher Education, p. A10.

Bothell, T., \& Henderson, T. (2002, October). Evaluating the return on investment of faculty development. Preconference workshop conducted at the 27th annual Professional and Organizational Development Network in Higher Education Conference, Atlanta, GA. 
Bothell, T., \& Henderson, T. (2003). Evaluating the return on investment of faculty development. In C. Wehlburg \& S. Chadwick-Blossey (Eds.), To improve the academy: Vol. 21. Resources for faculty, instructional, and organizational development (pp. 51-69). San Francisco, CA: Jossey-Bass.

Brownwell, J. E., \& Swayner, L. E. (2010). Five high-impact practices: Research on learning outcomes, completion, and quality. Washington, DC: Association of American Colleges and Universities.

Burkin, D., Chism, N.V.N., Frerichs, C., \& Wehlburg, C. (2003, October). New borizons in assessing faculty development. Paper presented at the 28 th annual Professional and Organizational Development Network in Higher Education Conference, Denver, $\mathrm{CO}$.

Cafarelli, L. K., \& Jones, K. M. (2002, October). Planning and conducting meaningful program evaluation. Paper presented at the 27 th annual Professional and Organizational Development Network in Higher Education Conference, Atlanta, GA.

Ewing, C., \& Sorcinelli, M. D. (n.d.). The value of a teaching center. Retrieved from www.podnetwork.org/faculty_development/values.htm

Faculty and TA Development, Ohio State University. (2004). Assessing our work: Developing an integrated data-driven evaluation system [CD]. Columbus, $\mathrm{OH}$ : Author.

Freire, P. (1972). Creating alternative research methods: Learning to do it by doing it. In B. Hall, A. Gillette, \& R. Tandon (Eds.), Creating knowledge: A monopoly? Participatory research in development (pp. 29-37). Toronto, Canada: International Council for Adult Education.

Glenn, D. (2009, August 18). Wary of budget knife, teaching centers seek to sharpen their role. Chronicle of Higher Education. Retrieved from http:// chronicle.com/article/Wary-of-Budget-Knife-Teaching/48049/

Gosling, D., Chism, N.V.N., \& Sorcinelli, M. D. (2008, June). The future of faculty/educational development: An international perspective. Paper presented at the biennial meeting of the International Consortium for Educational Development Conference, Salt Lake City, UT.

Guskey, T. R. (2000). Evaluating professional development. Thousand Oaks, CA: Corwin Press.

Kuhlenschmidt, S. (2011). Distribution and penetration of teaching-learning development units in higher education: Implications for strategic planning and research. In J. E. Miller \& J. E. Groccia (Eds.), To improve the academy: Vol. 29. Resources for faculty, instructional, and organizational development (pp. 274-287). San Francisco, CA: Jossey-Bass.

Mullinix, B. B. (2008). Credibility and effectiveness in context: An exploration of the issues surrounding the faculty status of faculty developers. In D. R. Robertson \& L. B. Nilson (Eds.), To improve the academy: Vol. 26. 
Resources for faculty, instructional, and organizational development (pp. 173-198). San Francisco, CA: Jossey-Bass.

Nilson, L. B. (2003, March). Justifying our existence: Can faculty development survive the budget cutting? Plenary session presented at the 24th annual Sharing Conference of the Southern Regional Faculty and Instructional Development Consortium, Atlanta, GA.

Nuhfer, E. B., Blodgett, M., Fleisher, S., \& Griffin, J. (2010). Supporting non-tenure faculty with time- and cost-effective faculty development. Metropolitan Universities, 21(2), 107-126.

Nuhfer, E. B., Cunningham, T., Parnell, G., Johnston, K. M., Bothell, T. W., Henderson, T. W., . . N Nilson, L. B. (2003, October). Reaping the priceless returns of faculty development. Roundtable conducted at the $28 \mathrm{th}$ annual Professional and Organizational Development Network in Higher Education Conference, Denver, $\mathrm{CO}$.

Nuhfer, E. B., Mullinix, B. B., \& Nilson, L. B. (2009, October). Faculty development as a hazardous occupation. Roundtable conducted at the 34th annual Professional and Organizational Development Network in Higher Education Conference, Houston, TX.

Patton, M. Q. (1998). Utilization-focused evaluation. Thousand Oaks, CA: Sage.

Strauss, A., \& Corbin, J. (1998). Basics of qualitative research: Techniques and procedures for developing grounded theory (2nd ed.) Thousand Oaks, CA: Sage.

U.S. Department of Labor, Bureau of Labor Statistics. (2011). Occupational outlook handbook, 2010-11 edition, teachers-postsecondary. Retrieved from www.bls.gov/oco/ocos066.htm\#emply

Way, D. G., Carlson, V. M., \& Piliero, S. C. (2002). Evaluating teaching workshops: Beyond the satisfaction survey. In D. Lieberman \& C. Wehlburg (Eds.), To improve the academy: Vol. 20. Resources for faculty, instructional, and organizational development (pp. 94-106). San Francisco, CA: Jossey-Bass. 